\title{
HUBUNGAN MOTIVASI KERJA PERAWAT DENGAN KINERJA PERAWAT DI RUANG RAWAT INAP RUMAH SAKIT ROYAL PRIMA MEDAN TAHUN 2019
}

\author{
BREMA PRIMA ${ }^{1}$, HERBERT WAU ${ }^{2}$, MARLINANG SIAGIAN ${ }^{3}$ \\ 1,2,3 UNIVERSITAS PRIMA INDONESIA \\ Email : bremaprima97@gmail.com
}

DOI : https://doi.org/10.35451/jkf.v2i1.214

\begin{abstract}
Motivation which means "encouragement" or "driving force". Motivation questions how to direct the power and potential of subordinates to want to work together productively in achieving and realizing specified goals. The purpose of this study was to determine the interpersonal relationship, self-development and workload with the performance of nurses in the inpatient rooms of the Royal Prime Hospital. This type of research used in this study is an analytic survey research using cross sectional design. The population of this study were all nurses in the inpatient room of the royal prima medan hospital, as many as 40 nurses. The sampling technique in this study was Total Sampling for case groups of 40 respondents. The results of this study were statistically tested using the Chi Square test with a 95\% confidence level using the SPSS program version 16.0. The results showed that there was a relationship between Workload and Nurse Performance in the Inpatient Room at Royal Prima Medan Hospital with each $p$-value of $a(0.783>0.05),(0.783>0.05),(0.017<0,05)$. The conclusion is that there is a relationship between workload and nurses' performance in the inpatient hospital at the royal prima medan hospital.
\end{abstract}

Keywords: Leadership Function (Planning, Supervision and Decision Making), Work Motivation of Health Workers

\section{PENDAHULUAN}

World Health Organization (WHO) menyatakan bahwa Indonesia masuk dalam 5 negara dengan motivasi tenaga kesehatannya paling rendah, selain Vietnam, Argentina, Nigeria dan India, hal ini disebabkan oleh kurangnya jumlah tenaga kerja yang dilihat dari tingkat pemenuhan kesejahteraan, berbagai pendapat mengatakan tenaga kesehatan merupakan faktor penting dalam tercapainya pembangunan kesehatan. Tenaga kesehatan sangat mempengaruhi hingga $80 \%$ didalam tercapainya tingkat kesehatan yang baik. Negara Indonesia merupakan negara yang menghadapi kurang tercapainya pemenuhan SDM kesehatan, baik itu dalam aspek jumlah perawat ataupun dalam pendistribusinya. (WHO, 2006).

Rasio perawat di Indonesia tahun 2013 adalah 89,9 per 100.000 penduduk, dengan rentang 31,3-327,1 per 100.000 penduduk. Berdasarkan pencapaian Indonesia Sehat 117,5 tenaga perawat per 100.000 masyarakat, secara nasional belum memenuhi target sehingga membuat kurangnya kepuasan pasien akan 
pelayanan kesehatan yang diberikan perawat dan kinerja perawat belum dilakukan secara maksimal yang ditimbulkan karena faktor kurangnya sumber daya khususnya pada bagian keperawatan (Depkes RI, 2013).

Undang - Undang Nomor 36 Tahun 2009 tentang Kesehatan mengamanatkan bahwa pemerintah merupakan faktor penting dalam memberikan pemenuhan tenaga kesehatan bagi masyarakat untuk memperoleh tingkat kesehatan yang semaksimalnya, seperti pemenuhan tenaga kesehatan, fasiltas pelayanan kesehatan, perbekalan kesehatan, serta teknologi dan produk teknologi (Kemenkes RI, 2015).

Derajat kesehatan yang optimal dapat dicapai oleh perawat dengan adanya motivasi kerja. Motivasi kerja yang tinggi dalam lingkungan kerja maka perawat akan merasakan rasa bangga, puas dalam melakukan pekerjaannya secara tuntas. Permasalahan yang ada sampai sekarang adalah kurang dilakukannya oleh Pihak Rumah Sakit dalam pengembangan diri atau pemberian reward seperti kenaikan jabatan atas apa yang dicapai oleh perawat sebagai bentuk meningkatkan motivasinya (Notoadmodjo, 2007).

Kinerja merupakan hasil yang dicapai seorang menurut ukuran yang berlaku dalam kurun waktu tertentu, berkenaan dengan pekerjaan serta perilaku dan tindakan. Kinerja yang diberikan merupakan hasil capaian terhadap hasil kerja yang dijalankan perawat guna tujuan pelayanan keperawatan yang didasari oleh standar keperawatan, indikator kinerja sangat dibutuhkan untuk bisa mengukur melihat capaian yang telah dilalui oleh perawat (Suwanto, 2011).

Perawat kehilangan motivasi tidak selalu mudah karena jarang diungkapkan. Namun hal ini dapat ditinjau dari perubahan sikap yang terjadi pada dirinya yang dapat diamati. Tanda-tanda yang mempunyai motivasi kurang bagus adalah : tidak bersedia bekerja sama, tidak mau menjadi sukarelawan, selalu datang terlambat,pulang cepat dan tidak hadir tanpa adanya keterangan ,memperpanjang waktu istirahat, tidak menepati tanggal waktu tugas, tidak mengikuti aturan yang ditetapkan, selalu merasa tidak bersemangat, saling menyalahkan, dan tidak mematuhi peraturan (Triana, 2015).

Ayu Amelia Fitri (2014), tentang Faktor-Faktor Yang Berhubungan Dengan Motivasi Kerja Pegawai Di Puskesmas IV Koto Agam Kabupaten Agam. Hasil penelitian ini adalah dari analisa univariat diperoleh motivasi kerja pegawai rendah $51,4 \%$. Hubungan antara tanggung jawab dengan motivasi kerja, dilihat dari hasil penelitian didapatkan tanggung jawab pekerjaan dengan motivasi kerja yang rendah $78,9 \%$. Hasil ujistatistik diperoleh adanya hubungan bermakna antar tanggung jawab perkerjaan dengan motivasi kerja pegawai $p=0,001$ dan $\mathrm{OR}=16,25$. Rendahnya tanggung jawab terlihat dari banyaknya pegawai yang menunda-nunda menyelesaikan pekerjaanya, datang tidak tepat waktu, melakukan pekerjaan lain diluar pekerjaan. Dan hubungan interpersonal dengan motivasi kerja pegawai, dilihat dari hasil penelitain hubungan interpersonal dan motivasi kerja pegawai yang rendah $78,9 \%$. Hasil uji statistik didapatkan adanya hubungan yang signifikan dari hubungan interpersonal dengan motivasi kerja pegawai $p=0,001$. Rendahnya hubungan sesama pegawai dipengaruhi kurang harmonis, baik di satu ruang maupun beda ruang.

Rumah Sakit Royal Prima merupakan Rumah Sakit Tipe B. Rumah Sakit ini mempunyai kapasitas 250 
tempat tidur dan memiliki jumlah karyawan 328 orang, 121 tenaga medis dan 106 paramedik perawat dengan latar belakang yaitu Spesialis, S2, Ners, S1 Kep dan DIII Kep.

Data yang diperoleh peneliti di Rumah Sakit Royal Prima Medan selama tiga tahun terakhir menunjukkan data kunjungan pasien rawat inap yaitu dari tahun 2015 sebanyak 8.059, tahun 2016 sebanyak 12.191 dan pada tahun 2017 sebanyak 15.600. Peningkatan kunjungan pasien untuk rawat inap dikarenakan pasien yang berobat ke Rumah Sakit Royal Prima Medan mendapatkan pelayanan BPJS yang baik dibandingkan pelayanan di Rumah Sakit lainnya, pasien juga merasa Rumah Sakit Royal Prima Medan tersebut lebih dekat dengan rumahnya dan hanya Rumah Sakit tersebut yang ada disekitar tempat tinggalnya, dan dokter yang berjaga di Rumah Sakit tersebut sering berada di tempat, walaupun terjadi peningkatan pasien rawat inap di Rumah Sakit Royal Prima Medan akan tetapi masih ditemukannya permasalahan mengenai kinerja perawat di Rumah Sakit tersebut.

Berdasarkan hasil survei awal dan wawancara penelitian terhadap perawat dan pasien di Rumah Sakit Royal Prima Medan, menurut hasil wawancara dengan pasien diperoleh kinerja perawat ini belum maksimal, hal ini terlihat dari masih terdapat pasien merasa kurang puas dengan pelayanan kesehatan yang diberikan kepadanya, seperti masih terdapat kurangnya kesigapan perawat pada saat pasien membutuhkannya seperti saat penggantian infus, kadang perawat tidak menyediakan bantal untuk pasien yang rawat inap, jarangnya perawat membangun komunikasi yang baik dengan pasien, dan dari hasil wawancara dengan perawat terdapat perawat yang memiliki motivasi kerja yang baik sehingga kinerja yang diberikannya dapat dikatakan maksimal, tetapi terdapat juga beberapa perawat yang menyatakan kurangnya motivasi mereka dalam hal hubungan interpersonal di dalam kelompok kerja, dan hubungan kerja sama dengan teman-teman seprofesi maupun dokter yang membuat kinerja perawat yang diberikan kepada pasien kurang maksimal.

Berdasarkan data yang diperoleh peneliti dari kepala unit ruang rawat inap mengenai tingkat kehadiran perawat di Ruang Rawat Inap Rumah Sakit Royal Prima Medan masih banyak perawat yang kehadirannya kurang maksimal seperti datang terlambang namun pulang lebih awal, saat peneliti mewawancara perawat untuk mengetahui apa yang menyebabkan kehadiran perawat tersebut kurang maksimal, perawat mengatakan jarak tempuh antara rumah dengan rumah sakit terlalu jauh, beban kerja yang terlalu banyak tidak sesuai dengan gaji yang mereka terima, kurangnya dukungan dari pihak Rumah Sakit dalam hal mengadakan seminar yang dapat membuat motivasi kerja lebih tinggi.

Berdasarkan latar belakang diatas, maka penulis tertarik untuk melakukan penelitian tentang "Hubungan Motivasi Kerja Perawat dengan Kinerja Perawat Di Ruang Rawat Inap Rumah Sakit Royal Prima Medan Tahun 2019".

\section{METODE PENELITIAN}

Jenis penelitian survey analitik dengan pendekatan cross sectional yaitu untuk menganalisis hubungan motivasi kerja perawat dengan kinerja perawat di ruang rawat inap rumah sakit royal prima medan tahun 2019 dan dilakukan pada bulan Januari 2019. Populasi berjumlah 40 perawat dan sampel 40 perawat menggunakan metode total sampling. Alat untuk pengumpulan data adalah kuesioner, dan untuk wawancara 
mendalam diperlukan pedoman wawancara. Untuk mengetahui tingkat kinerja para perawat. Data yang telah dikumpulkan diolah dengan analisis univariat dan bivariat (Notoadmodjo, 2012).

3. HASIL
Adapun hasil penelitian ini sebagai berikut:

Analisis Univariat

Analisis univariat dilakukan untuk mengetahui distribusi frekuensi berdasarkan umur, lama kerja, jenis kelamin, pendidikan di Rumah Sakit Royal Prima Medan Tahun 2019.

Tabel 1.

Distribusi Kategori Berdasarkan Umur, Lama Kerja, Jenis Kelamin, Pendidikan

\begin{tabular}{ccc}
\hline \multicolumn{1}{c}{ Variabel } & Jumlah (n) & $\begin{array}{c}\text { Persentase } \\
(\mathbf{\%})\end{array}$ \\
\hline Umur & & \\
a. $\leq 25$ Tahun & 27 & 57,4 \\
b. $>25$ Tahun & 17 & 36,2 \\
\hline Total & $\mathbf{4 0}$ & $\mathbf{1 0 0}$ \\
\hline Lama Kerja & & \\
a. 1-2 Tahun & 27 & 67,4 \\
b. 3-4 Tahun & 11 & 27,5 \\
C. 5-6 Tahun & 2 & 5,0 \\
\hline Total & $\mathbf{4 0}$ & $\mathbf{1 0 0}$ \\
\hline Jenis Kelamin & & 35,0 \\
a. Laki-Laki & 14 & 65,0 \\
b. Perempuan & 26 & $\mathbf{1 0 0}$ \\
\hline Total & $\mathbf{4 0}$ & \\
\hline Pendidikan & & 97,5 \\
a. D3 & 39 & $\mathbf{1 0 0}$ \\
b. S1 & 1 & \\
\hline Total & $\mathbf{4 7}$ & \\
\hline
\end{tabular}

Berdasarkan tabel 3.1 diperoleh distribusi frekuensi kelompok Umur responden, mayoritas responden kelompok $\leq 25$ Tahun sebanyak 26 orang $(65.0 \%)$ dan minoritas kelompok umur $>25$ Tahun sebanyak 14 orang (35.0\%).

Berdasarkan distribusi frekuensi kelompok Lama Kerja, responden kelompok 1-2 Tahun sebanyak 27 orang (67.5\%), dan kelompok 3-4 Tahun sebanyak 11 orang (27.5\%), dan kelompok 5-6 Tahun sebanyak 2 orang (5.0\%).

Berdasarkan distribusi frekuensi Jenis Kelamin dari 40 responden, mayoritas responden berjenis kelamin Perempuan sebanyak 26 orang (65.0\%) dan minoritas berjenis kelamin laki-laki sebanyak 14 orang (35.0\%).

Berdasarkan distribusi frekuensi Pendidikan responden, mayoritas responden kelompok D3 sebanyak 39 orang $(97.5 \%)$ dan minioritas kelompok S1 sebanyak 1 orang $(2,5 \%)$. 


\section{Analisa Bivariat}

Tabel 2. Hubungan Interpersonal, Pengembangan Diri, Beban Kerja Dengan Kinerja Perawat Di Ruang Rawat Inap Rumah Sakit Royal Prima Medan Tahun 2019

\begin{tabular}{|c|c|c|c|c|c|c|c|}
\hline \multirow{3}{*}{ Variabel } & \multicolumn{4}{|c|}{ Kinerja Perawat } & \multicolumn{2}{|c|}{ Total } & \multirow[t]{3}{*}{$\begin{array}{c}\mathbf{P} \\
\text { Value }\end{array}$} \\
\hline & \multicolumn{2}{|c|}{ Baik } & \multicolumn{2}{|c|}{ Tidak Baik } & \multirow{2}{*}{$\mathrm{N}$} & \multirow{2}{*}{$\%$} & \\
\hline & $\mathrm{N}$ & $\%$ & $\mathrm{n}$ & $\%$ & & & \\
\hline $\begin{array}{l}\text { Hubungan } \\
\text { Interperson: }\end{array}$ & & & & & & & \multirow{3}{*}{0,783} \\
\hline Baik & 9 & 25,7 & 26 & 74,3 & 35 & 100 & \\
\hline Tidak Baik & 1 & 20,0 & 4 & 80,0 & 5 & 100 & \\
\hline \multicolumn{8}{|c|}{$\begin{array}{l}\text { Pengembangan } \\
\text { Diri }\end{array}$} \\
\hline Baik & 9 & 25,7 & 26 & 74,3 & 35 & 100 & \multirow{2}{*}{0,783} \\
\hline Tidak Baik & 1 & 20,0 & 4 & 80,0 & 5 & 100 & \\
\hline \multicolumn{8}{|l|}{ Beban Kerja } \\
\hline Berat & 10 & 35,7 & 18 & 64,3 & 28 & 100 & \\
\hline Ringan & 0 & 0,0 & 12 & 100 & 12 & 100 & 0,017 \\
\hline
\end{tabular}

Hubungan interpersonal dengan kinerja perawat diperoleh dari 35 responden mayoritas yang menjawab Kinerja Perawat Tidak Baik tetapi menilai Hubungan Interpersonal Baik sebanyak 26 orang (74.3\%), dan minoritas yang menjawab Kinerja Perawat Baik dan menilai Hubungan Interpersonal Baik sebanyak 9 orang $(25.7 \%)$, dan dari 5 responden mayoritas perawat yang menilai Kinerja Perawat Tidak Baik dan Hubungan Interpersonal Tidak Baik sebanyak 4 orang $(80.0 \%)$, dan minoritas yang menjawab Kinerja Perawat Baik tetapi Hubungan Interpersonal Tidak Baik sebanyak 1 orang (20.0\%).

Hubungan pengembangan diri dengan pemanfaatan pelayanan antenatal care diperoleh Dari 35 responden mayoritas yang menjawab Kinerja Perawat Tidak Baik tetapi menilai Pengembangan Diri Baik sebanyak 26 orang (74.3\%), dan minoritas yang menjawab Kinerja
Perawat Baik dan menilai Pengembangan Diri Baik sebanyak 9 orang $(25.7 \%)$, dan dari 5 responden mayoritas perawat yang menilai Kinerja Perawat Tidak Baik dan Pengembangan Diri Tidak Baik sebanyak 4 orang $(80.0 \%)$, dan minoritas yang menjawab Kinerja Perawat Baik tetapi Pengembangan Diri Tidak Baik sebanyak 1 orang $(20.0 \%)$

Dari 28 responden mayoritas yang menjawab Kinerja Perawat Tidak Baik dan menilai Beban Kerja Berat sebanyak 18 orang (64.3\%), dan minoritas yang menjawab Kinerja Perawat Baik dan menilai Beban Kerja Berat sebanyak 10 orang (35.7\%), dan dari 12 responden mayoritas perawat yang menilai Kinerja Perawat Tidak Baik dan Beban Kerja Ringan sebanyak 12 orang $(10.0 \%)$, dan minoritas yang menjawab Kinerja Perawat Baik Beban Kerja Ringan sebanyak 0 orang $(0.0 \%)$ 


\section{PEMBAHASAN}

\section{Hubungan Interpersonal dengan Kinerja Perawat}

Hasil analisis bivariat dengan menggunakan uji chi-square diperoleh nilai $\mathrm{p}$ value $=0.783$ artinya $\mathrm{Ho}$ diterima, ini menunjukkan bahwa tidak ada hubungan yang signifikan antara hubungan interpersonal dengan kinerja perawat di Ruang Rawat Inap Rumah Sakit Royal Prima Medan Tahun 2019.

Hasil penelitian Kapalawi, dkk (2015) dengan uji Regresi linier didapatkan adanya pengaruh yang signifikan antara Hubungan Interpersonal, dengan Kinerja Perawat, yang paling besar memberikan pengaruhnya dengan kinerja perawat (Kapalawi I, dkk. 2013).

Tetapi tidak sejalan dengan penelitian yang dilakukan oleh Pasinringi, dkk (2014) yaitu mengatakan tidak terdapatnya hubungan yang signifikan antara hubungan antar manusia dengan kepuasan kerja perawat di ruang rawat inap RSUD Kabupaten Majene $(p=.0,007 ; p=0,039 ; p=0,000 ; a=$ 0,05 ) (Syahrir A, dkk, 2015).

Menurut teori (Yosep, 2007) Hubungan Interpersonal dapat dipengaruhi oleh beberapa faktor yang dapat mempengaruhi kinerja perawat kurang maksimal yang terdiri dari pengaruh perasaan, kedekatan dan daya tarik, faktor interaksi yaitu persamaan perbedaan. Hampir disetiap hubungan interpersonal antara pribadi maupun tidak, yang menjadikan hubungan efektif sehingga kinerja yang dihasilkan akan maksimal karena adanya interaksi antara perawat yang baik (Suparwati R, 2015).

Menurut asumsi peneliti bahwa pernyataan tentang Hubungan Interpersonal, perawat menjawab kuesioner dan menyatakan baik sebesar $(87,5 \%)$ karena banyak perawat yang menjawab kuesioner hubungan dan kerjasama antar perawat atau atasan berjalan lancar dan baik, dan beberapa perawat menjawab kuesioner menyatakan tidak baik sebesar $(12,5 \%)$, karena masih ada perawat yang kurang menjalin hubungan kerja sama dan hubungan yang kurang harmonis antar sesama perawat.

Berdasarkan hasil wawancara diketahui bahwa banyak responden yang memiliki tingkat Hubungan Interpersonal yang baik antara atasan dan bawahan atau antara perawat satu dengan yang lainnya dan tidak mempengaruhi kinerja yang mereka lakukan di Rumah Sakit tersebut.

\section{Hubungan Pengembangan Diri dengan Kinerja Perawat}

Hasil analisis bivariat dengan menggunakan uji chi-square diperoleh nilai $\mathrm{p}$ value $=0.783$ artinya $\mathrm{Ho}$ diterima, ini menunjukkan bahwa tidak ada hubungan yang signifikan antara Pengembangan Diri dengan kinerja perawat di Ruang Rawat Inap Rumah Sakit Royal Prima Medan Tahun 2019.

Hasil penelitian Ayu Amelia Fitri (2014), yang menunjukkan ada hubungan yang signifikan antara pengembangan diri dengan kinerja perawat Di Puskesmas IV Koto Agam Kabupaten Agam yaitu $p=0,001$ dan $\mathrm{OR}=16,25$ (Dalmont JP, dkk 1995).

Tidak sejalan dengan penelitian yang dilakukan oleh Sendow, dkk (2015) yang menunjukan bahwa ada hubungan yang signifikan antara perencanaan karir terhadap kinerja pegawai secara simultan tetapi variabel pengembangan diri tidak memiliki pengaruh yang signifikan terhadap kinerja perawat $p=0,812>0,05$ (Karir PP, 2015).

Menurut teori (Suyanto, 2009), mengatakan peningkatan pelayanan keperawatan (pengembangan diri) 
dapat ditingkatkan dengan cara memaksimalkan kinerja perawat dengan peningkatan pengetahuan melalui pengembangan diri, Supervisi merupakan segala bentuk dukungan dari pihak-pihak yang terkait kepada perawat yang ditujukan untuk perkembangan para perawat dan staf lainnya dalam mencapai tujuan asuhan keperawatan. Selain itu, perawat pelaksana akan diberikannya dorongan positif agar mau meningkatkan kemampuan dalam dirinya (Suyanto,dkk, 2011).

Menurut asumsi peneliti bahwa pernyataan tentang Pengembangan Diri, perawat menjawab kuesioner dan menyatakan baik sebesar $(87,5 \%)$ karena banyak perawat yang menjawab baik pada kuesioner yang menyatakan apakah ada usaha rumah sakit dalam pengembangan dan pelatihan, dan perawat memiliki kesempatan mengikuti pendidikan dan pelatihan seperti diklat, dan beberapa perawat yang menjawab kuesioner menyatakan tidak baik sebesar (12,5\%), karena tidak semua perawat setuju dengan pernyataan kuesioner bahwa rumah sakit memiliki usaha dalam pengembangan dan pelatihan, dan beberapa perawat tidak menempati posisi yang sesuai dengan kemampuannya.

Berdasarkan hasil wawancara diketahui bahwa banyak responden yang menyatakan Pengembangan Diri yang dilakukan oleh pihak Rumah Sakit Royal Prima sudah sangan baik dan berjalan lancer seperti diadakannya pelatihan, seminar, diklat, promosi kenaikan pangkat.

\section{Hubungan Beban Kerja dengan Kinerja Perawat}

Hasil analisis bivariat dengan menggunakan uji chi-square diperoleh nilai $p$ value $=0.017$ artinya Ho ditolak, ini menunjukkan bahwa ada hubungan yang signifikan antara Beban Kerja dengan kinerja perawat di Ruang Rawat Inap Rumah Sakit Royal Prima Medan Tahun 2019.

Berdasarkan penelitian yang di dilakukan Yulianto (2012), di ruang Mawar Rumah Sakit Umum Daerah Jombang dengan koefisiensi korelasi sebesar 0,548 dengan tingkat signifikan $0,019 \quad(p<0,05)$ memperoleh hasil beban kerja responden dengan kategori beban kerja ringan yaitu 16 responden $(89,9 \%)$ dan kinerja perawat dalam memberikan asuhan keperawatan dengan kategori amat baik 3 responden $(16,7)$ dan kategori baik sebanyak 11 responden $(61,1 \%)$ ini mendapatkan kesimpulan adanya hubungan antara beban kerja dengan kinerja perawat (Dian Husada, 2011)

Tetapi tidak sejalan dengan penelitian yang dilakukan di Rumah Sakit Tk II Kesdam Iskandar Muda Banda Aceh Tahun 2014, penelitian didapatkan bahwa tidak ada pengaruh antara beban kerja perawat dengan kinerja perawat dengan p.value $0.277>0.05$ (Dalmont JP, dkk 1995).

Menurut teori (Ilyas, 2004), mengatakan beban kerja berkaitan dengan kualitas perawat seperti kinerja yang dihasilkan. Beban kerja yang tinggi dapat menyebabkan terjadinya keletihan dan kelelahan bagi perawat.keletihan dan kelelahan perawat dapat terjadi jika perawat bekerja lebih dari $80 \%$ waktu kerja. Bila beban kerja perawat dikatakan tinggi atau tidak sesuai, maka dapat mempengaruhi kinerja perawat itu sendiri (Ramadini I, dkk, 2015).

Menurut asumsi peneliti bahwa pernyataan tentang Beban Kerja, perawat menjawab kuesioner dan menyatakan beban kerja berat sebesar $(70,0 \%)$ karena banyak perawat yang menjawab ya pada kuesioner yang menyatakan apakah pekerjaan terlalu 
berat, dan terlalu banyak menghabiskan energi, dan beberapa perawat yang menjawab kuesioner menyatakan beban kerja ringan sebesar $(30,0 \%)$, karena tidak semua perawat setuju dengan pernyataan kuesioner bahwa beban kerja yang diberikan terlalu banyak dan terlalu menghabiskan energi, dan perawat tidak setuju tentang pernyataan yang menyatakan mereka terbebani melakukan tindakan non medis seperti mengurus administrasi pasien.

Berdasarkan hasil wawancara diketahui bahwa banyak responden yang memiliki tingkat beban kerja berat karena banyaknya pasien yang berkunjung, perawat dituntut agar siap siaga dalam hal menangani pasien, tetapi shift yang diberikan hanya 2 kali dalam sehari, jumlah perawat yang kurang maksimal tidak sebanding dengan jumlah pasien yang berkunjung di rumah sakit tersebut, dan kurangnya waktu istirahat yang diberikan kepada perawat sehingga mempengaruhi tingkat kinerja dalam hal melakukan pekerjaan mereka.

\section{KESIMPULAN DAN SARAN Kesimpulan}

1. Tidak ada hubungan yang signifikan antara Hubungan Interpersonal Dengan Kinerja Perawat di Ruang Rawat Inap Rumah Sakit Royal Prima Medan Tahun 2019.

2. Tidak ada hubungan yang signifikan antara Pengembangan Diri Dengan Kinerja Perawat di Ruang Rawat Inap Rumah Sakit Royal Prima Medan Tahun 2019.

3. Ada hubungan yang signifikan antara Beban Kerja Dengan Kinerja Perawat di Ruang Rawat Inap Rumah Sakit Royal Prima Medan Tahun 2019.

\section{Saran}

1. Diharapkan agar pihak terkait untuk menambahkan jumlah shift perawat agar Beban Kerja yang diterima oleh perawat tidak terlalu tinggi.

2. Diharapkan agar menambahkan jumlah perawat yang ada di Ruang Rawat inap Rumah Sakit Royal Prima Medan.

3. Perlu adanya konseling kepada responden terkait Beban Kerja yang mereka terima dalam menjalankan tugas nya sebagai perawat.

\section{DAFTAR PUSTAKA}

Depkes RI, (2013), Ringkasan Eksekutif Data dan Informasi Kesehatan Provinsi Sumatera. Pusat Data dan Informasi, Jakarta : Depkes RI : 2013.

Dalmont JP, Gazengel B, Gilbert J, Kergomard J. Some aspects of tuning and clean intonation in woodwinds. Appl Acoust. 1995;46(1):19-60.

Dalam P, Asuhan M. Jurnal Keperawatan \& Kebidanan - Stikes Dian Husada Mojokerto. :69-73.

Hartika $H$, Tinggi S, Stik I, Pendidikan $Y$, Ypt T. MOTIVASI KERJA TENAGA KESEHATAN DI PUSKESMAS WALENRANG KABUPATEN LUWU Motivation of Health Workers in Walenrang Community Health Center Luwu Regency. 2014;6570.

Kementerian Kesehatan Tahun 20152019 [Online]. dari :http://www.depkes.go.id/resour ces/download/infopublik/Renstra2015.pdf

Karir PP, Dan P, Manajemen J, Ekonomi F. PADA MUSEUM NEGERI PROVINSI SULAWESI UTARA THE INFLUENCE OF CAREER 
PLANNING， TRAINING AND CAREER. 2015;15(05):635-45.

Kepuasan A, Kab R, Majene R, Majene RK, Majene RK. HUBUNGAN MOTIVASI KERJA DENGAN KEPUASAN PERAWAT PADA UNIT RAWAT INAP RUMAH SAKIT UMUM DAERAH KABUPATEN MAJENE Work Motivation Relationship with Nurse Satisfaction in Inpatient Units of Majene General Hospital Meilinda Sari , Noor Bahry Noor, Syahrir A. 2015;

Makta L, Noor HNB, Sc M, Kapalawi I, Mars MSPH. PENGARUH MOTIVASI KERJA DENGAN KINERJA PERAWAT PELAKSANA DI UNIT RAWAT INAP RS . STELLA MARIS MAKASSAR. 2013;

Notoatmodjo. Metodologi penelitian kesehatan.Jakarta: Rineka Cipta; 2010.

Profil Rumah Sakit; Rumah Sakit Royal Prima Medan 2018.

Publikasi N, Suparwati R, Studi P, Keperawatan I. STRES PERAWAT DI RUANG RAWAT INAP. 2015;

Perawat AK, Kinerja D. BAB II TINJAUAN TEORI A. Kinerja Perawat 1. Definisi Kinerja. 2011;9-28.

Ramadini I, Jasmita E. Hubungan Motivasi Dengan Kinerja Perawat Pelaksana. Ners. 2015;11(1):86101.

Setiyaningsih Y, Sukesi N, Kusuma BAM. Hubungan Motivasi dengan Kinerja Perawat di Ruang Rawat Inap RSUD Ungaran. Respository Progr Stud S1 IImu Keperawatan STIKES Telogorejo Semarang [Internet]. 2012;1-8. Available from:

http://ejournal.stikestelogorejo.a c.id/index.php/ilmukeperawatan/ article/view/150/175

Suwanto \& Priansa, D.J. (2011). Manajemen Sumber Daya
Manusia Dalam Organisasi Publik Dan Bisnis, Bandung, Alfrabeta.https://www.researchg ate.net/publication/308121247 P ENGEMBANGAN KARIER SEBAG AI FAKTOR PALING MEMPENGA RUHI KINERJA PERAWAT PELAK SANA

Triana, (2015), Hubungan Pemberian reward dan Pelatihan dengan Motivasi Kerja Tenaga Kesehatan Kesehatan.

WHO, (2006), Rencana Pembangunan Jangka Panjang Nasional 20112025. 